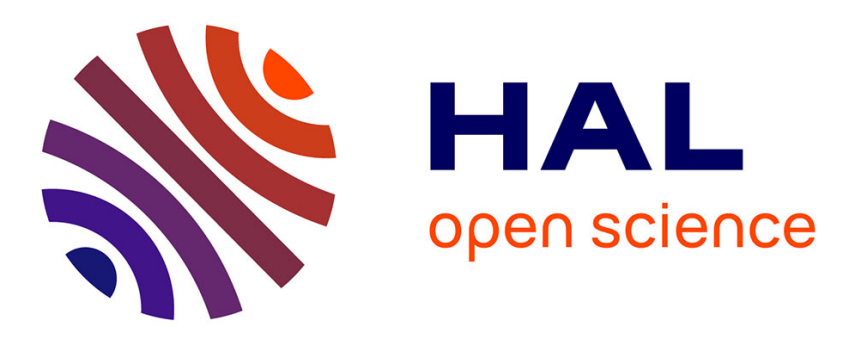

\title{
Surface modification of closed plastic bags for adherent cell cultivation
}

\author{
K. Lachmann, A. Dohse, M. Thomas, S. Pohl, W. Meyring, K.E.J. Dittmar, \\ W. Lindenmeier, C.-P. Klages
}

\section{- To cite this version:}

K. Lachmann, A. Dohse, M. Thomas, S. Pohl, W. Meyring, et al.. Surface modification of closed plastic bags for adherent cell cultivation. European Physical Journal: Applied Physics, 2011, 55 (1), 10.1051/epjap/2011100467 . hal-00719806

\section{HAL Id: hal-00719806 \\ https://hal.science/hal-00719806}

Submitted on 21 Jul 2012

HAL is a multi-disciplinary open access archive for the deposit and dissemination of scientific research documents, whether they are published or not. The documents may come from teaching and research institutions in France or abroad, or from public or private research centers.
L'archive ouverte pluridisciplinaire HAL, est destinée au dépôt et à la diffusion de documents scientifiques de niveau recherche, publiés ou non, émanant des établissements d'enseignement et de recherche français ou étrangers, des laboratoires publics ou privés. 


\title{
Surface modification of closed plastic bags for adherent cell cultivation
}

\author{
K. Lachmann ${ }^{1}$, A. Dohse ${ }^{1}$, M. Thomas ${ }^{1}$, S. Pohl ${ }^{2}$, W. Meyring ${ }^{3}$, K. E. J. Dittmar ${ }^{2}$, \\ W. Lindenmeier ${ }^{2}$, C.-P. Klages ${ }^{1}$ \\ ${ }^{1}$ Fraunhofer Institute for Surface Engineering and Thin Films IST, Bienroder Weg 54 E, 38108 \\ Braunschweig, Germany, \\ E-mail: kristina.lachmann@ist.fraunhofer.de, \\ Phone: +495312155683 \\ Fax: +495312155910
}

${ }^{2}$ Helmholtz Centre for Infection Research HZI, Inhoffenstr. 7, 38124 Braunschweig, Germany

${ }^{3}$ Städtisches Klinikum Braunschweig GmbH, Freisestr. 9/10, 38118 Braunschweig, Germany 


\section{Abstract:}

In modern medicine human mesenchymal stem cells are becoming increasingly important. However, a successful cultivation of this type of cells is only possible under very specific conditions. Of great importance, for instance, are the absence of contaminants such as foreign microbiological organisms, i.e. sterility, and the chemical functionalization of the ground on which the cells are grown. As cultivation of these cells makes high demands, a new procedure for cell cultivation has been developed in which closed plastic bags are used. For adherent cell growth chemical functional groups have to be introduced on the inner surface of the plastic bag. This can be achieved by a new, atmospheric-pressure plasma based method presented in this paper. The method which was developed jointly by the Fraunhofer IST and the Helmholtz HZI can be implemented in automated equipment as is also shown in this contribution.

Plasma process gases used include helium or helium-based gas mixtures $\left(\mathrm{He}+\mathrm{N}_{2}+\mathrm{H}_{2}\right)$ and vapours of suitable film-forming agents or precursors such as APTMS, DACH, and TMOS in helium. The effect of plasma treatment is investigated by FTIR-ATR spectroscopy as well as surface tension determination based on contact angle measurements and XPS spectroscopy. Plasma treatment in nominally pure helium increases the surface tension of the polymer foil due to the presence of oxygen traces in the gas and oxygen diffusing through the gaspermeable foil, respectively, reacting with surface radical centres formed during contact with the discharge. Primary amino groups are obtained on the inner surface by treatment in mixtures with nitrogen and hydrogen albeit their amount is comparably small due to diffusion of oxygen through the gas-permeable bag, interfering with the plasma-amination process. Surface modifications introducing amino groups on the inner surface turned out to be most efficient in the promotion of cell growth. 


\section{Introduction}

Living cells are used more and more frequently in modern medical applications such as stem cell therapy, blood transfusion, and bone marrow transplantation, or in the case of the treatment of deep burns. Of particular interest are mesenchymal stem cells. Successful cultivation of these cells requires very specific conditions with suitably functionalized surfaces providing fertile grounds for the cells. Such surfaces are currently fabricated using various methods including wet-chemical processes [1] modifying the surfaces by polyelectrolyte multilayer (PEM) [2,3] or self-assembly monolayer (SAM) $[4,5]$ coatings, UV-ozone treatment [6-8] and plasma processes [9-12], respectively.

Wet chemical methods, like coating with PEM, are often simple and can be used for different kinds of substrates though, for instance, polypropylene surfaces require suitable pre-treatment prior to PEM deposition. Generally the PEM deposition is relatively time-consuming and may in the case of the coating of bags lead to the production of large volumes of waste water. SAM coatings may result in a high density of functional group, but usually require goldcoated surfaces $[4,5]$. Therefore this method does not seem suitable for the production of cell culture bags. UV-ozone treatment of the bag may also not be the method of choice since it may accure undesired degradation of the polymer used.

Chemical functionalization of polymer surfaces by plasma treatment, introducing functional groups able to promote cell attachment, can be obtained using oxygen or nitrogen-containing gas mixtures [11-16].

Conventionally cell cultivation is carried out in open systems such as microtiter plates or petri dishes. However, with open systems cell cultures can be relatively easily contaminated. At Helmholtz Center for Infection Research (HZI) a new method was developed where closed 
plastic bags are used for cell cultivation of suspension cells. This approach efficiently reduces the risk of contamination of the cell cultures. For adherent cell growth the inner surfaces of the plastic bags have to be modified. This can be achieved by a new plasma process at atmospheric pressure developed at Fraunhofer IST, which is described in this contribution.

In the literature as well as in several patents various mostly low-pressure plasma based methods are described for the modification of the inner walls of plastic bottles, often to create barrier coatings [17-20]. There is also an example where a plasma at atmospheric pressure was ignited inside a closed bag [21], which was used for the inactivation of microbial organisms in the inside.

In this contribution the internal surface modification or coating of plastic bags by means of atmospheric-pressure plasmas so as to enable adherent cell growth on these surfaces is presented. Even during the coating process the plastic bags are not opened, which excludes the use of vacuum technique. In order to ignite a discharge exclusively inside the plastic bag a set-up needs to be created in which the bag contains a process gas with a sufficiently lower breakdown field strength compared with the gas surrounding the bag. If the surrounding gas is air, helium-based process gas mixtures lend themselves well for the purpose pursued in this paper. Typical process gases contained, apart from a large proportion of helium, nitrogen and hydrogen or suitable film-forming monomers, since with these the desired $\left(-\mathrm{NH}_{2}\right)$ or silanol (Si-OH) functions can be generated on the inner surface of the bag.

\section{Experimental}

Gas permeable and transparent bags made of polyolefin suitable for suspension cell culture (Miltenyi Biotec) were used for coating and adherent cell cultivation experiments. 
The surface modification consists of two main steps including filling of the bags with the process gas mixture and subsequent plasma treatment.

Filling of the plastic bags with the process gas was carried out using an automated filling system developed at Fraunhofer IST. The plasma surface modification processes investigated here can be classified into processes without and with deposition of coatings (PECVD). In the case of the non-coating treatment the process gases were of helium or mixtures of helium, nitrogen $(9-18 \%)$ and hydrogen $(1-2 \%)$. In the case of film deposition, monomers like 3-aminopropyl-trimethoxysilane (APTMS), 1.2-diaminocyclohexane $\quad(\mathrm{DACH}) \quad$ or tetramethoxysilane (TMOS) were added to the process gas using a bubbler system. A schematic drawing of the gas supply in the automated system is given in Fig. 1. In all experiments the total gas flow was set to $5 \mathrm{~L} \mathrm{~min}^{-1} \mathrm{STP}$, leading to a filling of the bag within a few seconds. The filling procedure included several consecutive cycles of emptying the bag by a de Laval nozzle and refilling it with the process gas in order to make sure that the process gas had the desired composition. Plasma treatment was performed using a DBD arrangement with electrodes located above and underneath the bag, so that the discharge ignited exclusively inside the bag upon application of an alternating voltage of sufficient magnitude [22]. The bags were fixed by the electrodes so that both surfaces were adjusted parallel to each other to improve film homogeneity. A schematic illustration of the electrode arrangement is given in Fig. 2. As a high voltage electrode a 150 x $300 \mathrm{~mm}^{2}$ steel electrode covered with a $3.4 \mathrm{~mm}$ thick glass plate as a dielectric was used, a thin aluminum plate $\left(150 \times 300 \mathrm{~mm}^{2}\right)$ covered with a $5 \mathrm{~mm}$ thick polyethylene sheet served as a ground electrode (see Fig. 2).

The unit for plasma treamtent was also integrated in the automated filling system. 
The discharge was powered by a generator HV 2000 series from Tantec SE (Lunderskov, Denkmark). Typical experiments were run with an electrical power of approx. $50 \mathrm{~W}$, an effective voltage of $9.75 \mathrm{kV}$ and a frequency of $22 \mathrm{kHz}$. Treatment duration was in the range of 5-20 s. Gas mixtures containing nitrogen and hydrogen apart from helium need higher breakdown voltages compared with pure helium. For experiments with these mixtures an increased effective voltage of $16.5 \mathrm{kV}$ was applied. The process parameters are summerized in Table 1.

After the plasma treatment the bags were emptied to remove residual process gas and subsequently purged and filled with nitrogen so as to avoid sticking together of the treated surfaces during storage.

APTMS (> $97 \%)$, DACH (99\%), and TMOS (98\%) were supplied by Sigma-Aldrich and were used without further purification. The purity of helium was $>99.999 \%$ (Air Liquide).

Surface analysis of the functionalized samples ( $\mathrm{He}, \mathrm{He}+\mathrm{N}_{2}+\mathrm{H}_{2}$ ) was performed on a PHI 5500 Multi-Technique XPS system from Perkin Elmer equipped with a $\mathrm{MgK}_{\alpha} \mathrm{X}$-ray source $(1253.6 \mathrm{eV})$ without monochromator and a vacuum better than $8 \cdot 10^{-9}$ mbar during the measurement. The collection angle was $45^{\circ}$ and the X-ray spot size $400 \mathrm{x} 400 \mu \mathrm{m}^{2}$. Peak deconvolution was done with the MultiPak Software V 5.0 from Physical Electronics [23].

Moreover, the modified internal surfaces of the bags were analyzed using FTIR-ATR spectroscopy (Nicolet 5700, Thermo Fisher Scientific Inc., Waltham, MA, USA) equipped with an MCT detector and a DuraSamplIR single-reflexion $45^{\circ}$ diamond ATR crystal using unpolarized light and a spectral resolution of $4 \mathrm{~cm}^{-1}$ for qualititative measurements of the film 
composition and a spectral resolution of $1 \mathrm{~cm}^{-1}$ for the determination of the amino group density on the derivatized samples.

The number of primary amino groups per square nanometer on surface functionalized polymer bags (treatment: $\mathrm{He}+\mathrm{N}_{2}+\mathrm{H}_{2}$ ) was determined by chemical derivatization with 4-trifluoromethyl-benzaldehyde (TFBA, > $98 \%$, Sigma-Aldrich) followed by quantitative FTIR-ATR measurements (CD FTIR-ATR) of the absorption band area generated by the vibrations of the $\mathrm{C}-\mathrm{CF}_{3}$ moieties in the resulting 4-trifluoromethyl-benzaldimines. A detailed description of the method is given in the literature [24].

Surface tensions were calculated from contact angles (OCA 60, dataphysics) using the approach of van Oss and Good expressing the total surface tension of a material as the sum of Lifshitz-van der Waals and Lewis acid-base components [25, 26]. Water (Milli-Q-grade), ethylene gylcol (> $99 \%$, Sigma-Aldrich) and diiodomethane (>99\%, Sigma-Aldrich) served as test liquids.

Cell cultivation of bone marrow mesenchymal stem cell was performed at the Helmholtz Centre for Infection Research (HZI, Braunschweig, Germany). A commercially availiable cell culture plate (Cellstar, Greiner BioOne) served as a control surface. The cells were incubated at $37{ }^{\circ} \mathrm{C}$ under a $5 \% \mathrm{CO}_{2}$ atmosphere. The culture media used was EMEM (Sigma-Aldrich). The media contained $10 \%$ fetal calf serum (FCS, PAN Biotech), 5 mM L-glutamine (Serva), 100 unit $\mathrm{ml}^{-1}$ penicilline (Sigma-Aldrich) and $100 \mu \mathrm{g} \mathrm{ml}^{-1}$ streptomycin (Serva). The cells were lifted with trypsin-EDTA solution (Biochrom) at 80-90 \% confluence and stained with DIOC6 and measured with a fluorescence microscope.

\section{Results and Discussion}




\subsection{Surface analysis}

Film composition and number density of functional groups was determined using different methods (for experimental detail see section 2). For surface analysis the bags had to be opened. From this moment the internal surface was exposed to air. However, since the plastic foil is permeable for air, $\mathrm{CO}_{2}$ and $\mathrm{H}_{2} \mathrm{O}$ vapour, it is assumed that the surface reactions with these gases were already completed, when surface analysis was carried out. It is not expected that the surface modification or the coating changed during the short period in which the analysis is accomplished.

Depending on the gas mixture used different chemical functionalities were incorporated on the surface or a thin coating was deposited (see Table 2). Surface functionalization was obtained in pure helium or in a mixture of helium with nitrogen and hydrogen resulting in the incorporation of chemical functional groups such as $-\mathrm{OH},-\mathrm{NH}_{2},-\mathrm{NH}$ on the polymer surface. PECVD coatings were produced using three different monomers. Tetramethoxysilane (TMOS) provides a plasma polymer terminated with $\mathrm{Si}-\mathrm{OH}$ groups (due to hydrolysis of surface methoxy functions by water migrating into the bag), while 3-aminopropyltrimethoxysilane (APTMS) was used to equip the surface with both $\mathrm{Si}-\mathrm{OH}$ and primary amino groups. Silicon-free amino group containing coatings were achieved using 1.2diaminocyclohexane (DACH).

The results in Table 3 show the increase of the surface tension from $26.3 \mathrm{mN} \mathrm{m}^{-1}$ for the reference sample to values up to $41.1 \mathrm{mN} \mathrm{m}^{-1}$ of a treated sample due to the incorporation of functional groups, depending on the gas mixture used. The increase of surface tension upon plasma treatment with pure helium is comparable to that of the modified polymer surfaces after incorporation of primary amino groups by plasma treatment in mixtures of helium, nitrogen and hydrogen or helium enriched with amino-containing film-forming agents. The 
increase in surface tension is due to a rise of the Lifshitz-van der Waals components $\gamma^{\mathrm{LW}}$ and, generally more pronounced, the rise in the acid-base components $\gamma^{\mathrm{AB}}$. For all treatments the electron-acceptor capacity $\gamma^{+}$is close to zero, whereas the electron-donor capacity $\gamma^{-}$indicates monopolar properties of the modified surfaces.

Exposure of the polypropylene surface to the He discharge leads to the formation of radicals on the polymer surface which will react with oxygen traces in the gas phase or oxygen, which diffuse through the gas-permeable polymer bag after the process. In these reactions oxygencontaining functional groups such as $-\mathrm{OH},-\mathrm{C}=\mathrm{O}$, and $-\mathrm{COOH}$ are formed on the polymer surface, resulting in an increased surface tension [27]. XPS measurements of the internal surface of treated and untreated plastic bags were performed of the inner surface of treated and untreated plastic bags. The results are given in Table 4 showing the elemental composition of the surfaces of the two samples. Even after a very short treatment time of $5 \mathrm{~s}$ the amount of oxygen bound on the inner polymer surface has doubled compared with the untreated material. For the reference sample $4.86 \%$ oxygen was determined at the surface, whereas the oxygen content on the helium-treated sample has risen to $10.17 \%$.

The coatings deposited on the internal surfaces of the plastic bags were characterized by FTIR-ATR spectroscopy. Results are shown in Fig. 3. For easier identification of the plasmainduced changes on the surface difference spectra were produced by subtracting a spectrum of the untreated material from the spectra of the treated material.

The FTIR-ATR spectra in Fig. 3 show the most prominent absorption bands characteristic of the molecular structure of the plasma polymer coating. In the case of TMOS-coated polymer bags the dominant peak at approx. $1050 \mathrm{~cm}^{-1}$ is attributed to $\mathrm{Si}-\mathrm{O}-\mathrm{Si}$ and $\mathrm{Si}-\mathrm{O}-\mathrm{C}$ vibrations. The absorption band of Si-O-H is located at wave numbers $>3000 \mathrm{~cm}^{-1}$. Silicon-free coatings were obtained by coating the polymer bag using 1.2-diaminocyclohexane (DACH) as 
precursor. Characteristic absorption bands are identified at $\sim 1650 \mathrm{~cm}^{-1}$ originating from the deformation vibration of primary and secondary amino groups while $\mathrm{N}-\mathrm{H}$ stretching vibrations are located at wave numbers $>3000 \mathrm{~cm}^{-1}$. In the case of APTMS-coated polymer bags the deposited coating contains primary amino groups as revealed by vibrations at $\sim 1650 \mathrm{~cm}^{-1},>3000 \mathrm{~cm}^{-1}$ and a Si-O-Si network $\left(\sim 1100 \mathrm{~cm}^{-1}\right)$ and additional Si-OH $\left(>3000 \mathrm{~cm}^{-1}\right)$.

Regarding different treatment times (Fig. 3 bottom), it can be seen that the precursor inside the bag was consumed within the first $5 \mathrm{~s}$ as indicated by the fact that no further differences in the FTIR-ATR spectra were observed in treatments of durations longer than $5 \mathrm{~s}$ (Fig. 3 bottom). To minimize damage of the polymer surface due to plasma contact, which is known to lead to the generation of low molecular weight oxidized material (LMWOM) [28] or to an etching of the coating, the plasma treatment time should be chosen as short as possible. By repeating the process several times, each time with fresh monomer added, the film thickness was increased. In Fig. 3 (bottom, 4 x $5 \mathrm{~s}$ ) this is shown for a coating where the deposition process was repeated four times. The plasma treatment time for each run was $5 \mathrm{~s}$ leading to a total treatment time of $20 \mathrm{~s}$. After each run the used process gas was completely refreshed.

The number of primary amino groups per square nm was determined by CD FTIR-ATR measurements as described in Ref. [24]. The required difference spectra were obtained by subtracting the derivatized sample from the non-derivatized sample spectra. The number of primary amino groups is then calculated from the area of the extinction of $-\mathrm{CF}_{3}$ vibrational bands, found after the reaction of 4-trifluoromethyl-benzaldehyde (TFBA) with primary amino groups. In Fig. 4 the difference spectra of a surface functionalized sample $(\mathrm{He}+9 \%$ $\mathrm{N}_{2}+1 \% \mathrm{H}_{2}$ ) and an APTMS-coated sample are shown with the characteristic absorption 
peak in the region where the $-\mathrm{CF}_{3}$ vibrational band appears. For polymer foils plasmafunctionalized with gas mixtures containing nitrogen and hydrogen about $0.7-\mathrm{NH}_{2} \mathrm{~nm}^{-2}$ were achieved after the admixture of $9 \%$ nitrogen and $1 \%$ hydrogen to $\mathrm{He}$, and slightly more primary amino groups, about $0.9-\mathrm{NH}_{2} \mathrm{~nm}^{-2}$, were achieved when a gas mixture containing $18 \%$ nitrogen and $2 \%$ hydrogen was used. By chemical derivatization of APTMS and DACH-coated plastic surfaces selectively the chemically accessible primary amino groups are detected. In the case of APTMS a density of $1-\mathrm{NH}_{2} \mathrm{~nm}^{-2}$ was determined after a plasma treatment time of $10 \mathrm{~s}$, whereas in the case of DACH up to $4-\mathrm{NH}_{2} \mathrm{~nm}^{-2}$ were detected under the same process conditions. It should be noted here that these densities are calculated under the assumption that the derivatization takes place only in the uppermost surface layer.

The comparatively low amount of primary amino groups obtained from nitrogen-containing gases or monomers containing primary amino groups can be explained by impurities of oxygen in helium and oxygen diffusing from the outside of the bag into the interior during the plasma treatment.

\subsection{Cell Cultivation}

Cell cultivation of bone marrow mesenchymal stem cells was performed at Helmholtz Centre for Infection Research. In Fig. 5 the effects of different surface modifications are compared. On day three of cell cultivation there was no significant difference found between the three types of coating. The density of growing cells seems to be comparable to cell cultivation on a conventional cell culture plate, whereas on the untreated polymer bag no adherent cell growth was observed. After 14 days of cultivation confluent cell growth was observed on the aminocontaining coatings, while on the TMOS-coated plastic surface the cells have detached. The supporting effect of nitrogen-rich plasma polymer films on cell cultivation is already described in the literature $[10,29]$ and is most probably due to positively charged protonated amino groups which can interact with negatively charged biomolecules at physiological $\mathrm{pH}$. 


\section{Conclusions}

Using gas mixtures of helium and suitable reactive species or film-forming agents, plastic bags can be modified for the use in adherent cell cultivation. Due to residual oxygen in the gas mixture or the diffusion of oxygen through the gas-permeable polymer wall even the treatment with pure helium leads to a rise in surface tension which is comparable to the surface tension achieved by coating with APTMS or surface functionalization in gas mixtures of helium, hydrogen and nitrogen. Traces of oxygen in the gas mixture also led to a reduced density of primary amino groups. Performing cell cultivation of adherent bone marrow mesenchymal stem cells the role of primary amino groups on the surface was highlighted. In the case of TMOS-coated plastic bags only initial adherence was observed, but after 14 days in culture the cells had detached. In contrast, with coatings based on amino group-containing monomers such as APTMS and DACH confluent cell growth on the modified surfaces is observed. In further experiments the plasma process should be optimized to generate higher concentrations of primary amino groups on the surface, e.g. to be able to perform more efficiently secondary modifications such as biotinylation or coupling of specific markers.

\section{Acknowledgements:}

The investigations were funded by the Federal Ministry of Economy and Technology of Germany (project No. 16INO548).

\section{References}

[1] L. Qian, W. M. Saltzman, Biomaterials 25, 1331 (2004). 
[2] K. Ren, L Fourel, C. Gauthier Rouvière, C. Albiges-Rizo, C. Picart, Acta Biomaterialia 6, 4238 (2010).

[3] O. V. Semenov, A. Malek, A. G. Bittermann, J. Vörös, H. Zisch, Tiss. Eng. A 15, 2977 (2009).

[4] R. Daw, I. M. Brook, A. J. Devlin, R. D. Short, E. Cooper, G. J. Leggett, J. Mater. Chem. 8, 2583 (1998).

[5] D. A. Stenger, J. H. Georger, C. S. Ducles, J. J. Hickman, A. S. Rudolph, T. B. Nielsen, S. M. McCort, J. M. Calvert, J. Am. Chem. Soc. 114, 8435 (1992).

[6] M. R. Davidson, S. A. Mitchell, R. H. Bradley, Colloids and Srfaces B: Biotinterfaces 34, 213 (2004).

[7] D. O. H. Teare, N. Emmison, C. Ton-That, R. H. Bradley, Langmuir 16, 2818 (2000).

[8] D. O. H. Teare, N. Emmison, C. Ton-That, R. H. Bradley, J. Coll. Interf. Sci. 234, 84 (2001).

[9] R. M. France, R. D. Short, R. A. Dawson, S. MacNeil, J. Mater. Chem. 8, 37 (1998).

[10] A. Harsch, J. Calderon, R. B. Timmons, G. W. Gross, J Neurosci. Meth. 98, 155 (2000).

[11] F. Mwale, H. T. Wang, V. Nelea, L. Luo, J. Antoniou, M. R. Wertheimer, Biomaterials 27, 2258 (2006).

[12] V. Nelea, L. Luo, C. N. Demers, J. Antoniou, A. Petit, S. Lerouge, M. R. Wertheimer, F. Mwale, J. Biomed. Mater. Res. 75A, 216 (2005).

[13] R. Dorai and M. J. Kushner, J. Phys. D: Appl. Phys. 36, 666 (2003).

[14] G. J. Courval, D. G. Gray, and D. A. I. Goring, J. Polym. Sci.: Polym. Lett. Ed. 14, 231 (1976).

[15] S. Guimond, I. Radu, G. Czeremuszkin, D.J. Carlsson and M.R. Wertheimer, Plasmas Polym. 7, 71 (2002). 
[16] F. Trucia-Marascu, P.-L. Girard-Lauriault, A. Lippitz, W. E. S. Unger, M. R. Wertheimer, Thin Solid Films 516, 7406 (2008).

[17] German patent DE19814865C2.

[18] M. Walker, F. Meermann, J. Schneider, K. Bazzoun, J. Feichtinger, A Schulz, J. Krüger, U. Schumacher, Surf. Coat. Techn. 201, 947 (2005).

[19] K. Teshima, Y. Inoue, H. Sugimura, O. Takai, Vacuum 66, 353 (2002).

[20] A. Grüninger, A. Bieder, A. Sonnenfeld, Ph. Rudolf, U. Müller, R. Hauser, Surf. Coat. Techn. 200, 4564 (2006).

[21] A. S. Chiper, W. Chen, E. Stamate; Proceedings ISPC 19; Bochum, Germany (2009).

[22] German patent DE102006036536 B3.

[23] K. Lachmann, B. Michel, C.-P. Klages, Plasma Proc. Poly. 6, S401 (2009).

[24] C.-P. Klages, A. Grishin, Plasma Process. Polym. 5, 368 (2008).

[25] C. J. van Oss, Interfacial Forces in Aqueous Media, Dekker, New York, (1994).

[26] C. J. van Oss, M. K. Chaudhury, R. J. Good, Chem. Rev. 88, 927 (1988).

[27] N. De Geyter, R. Morent, C. Leys, L. Gengembre, E. Payen, Surf. Coat. Techn. 201, 7066 (2007).

[28] L.-A. O’Hare, S. Leadley, B. Parbhoo, Surf. Interface Anal. 33, 335 (2002).

[29] P.-L. Girard-Laurialt, F. Mwale, M. Iordanova, C. Demers, P. Desjardins, M. R. Wertheimer, Plasma Process. Polym. 2, 262 (2005). 


\section{Figure captions}

Figure 1: Schematic depiction of the gas supply in the automated filling system.

Figure 2: Schematic illustration of the electrode arrangement used for plasma treatment

Figure 3: FTIR-ATR difference spectra of plastic bag coated with tetramethoxysilane (top left), 1.2-diaminocyclohexane (top right) and 3-aminopropyl-trimethoxysilane (bottom). Substrate-related absorptions bands were eliminated by subtracting the FITR-spectrum of an untreated polymer bag from the spectrum obtained after the treatment. The negative absorption bands in the spectra arise due to the attenuation of the substrate absorption because of film formation.

Figure 4: Cell cultivation of adherent bone marrow mesenchymal stem cells on the modified plastic bags at day 3 of cultivation (above) and at day 14 of cultivation (below). As control serves a commercial availiable cell culture plate, magnification 10x. 


\section{Table captions:}

Table 1: Process parameters for the plasma treatment of the closed bag systems.

Table 2: Gas mixture and film-forming agent and created surface functional groups.

Table 3: Surface tension components and total surface tensions $[\mathrm{mN} / \mathrm{m}]$ of the treated polymer depending on the gas mixture and the film-forming agent, resp., after $10 \mathrm{~s}$ of plasma treatment.

Table 4: Element composition determined by XPS-spectroscopy of helium-treated polymer samples.

Table 5: Element composition determined by XPS-spectroscopy of helium-treated polymer samples with add-mixtures of $\mathrm{N}_{2}$ and $\mathrm{H}_{2}$. 


\section{Figures:}

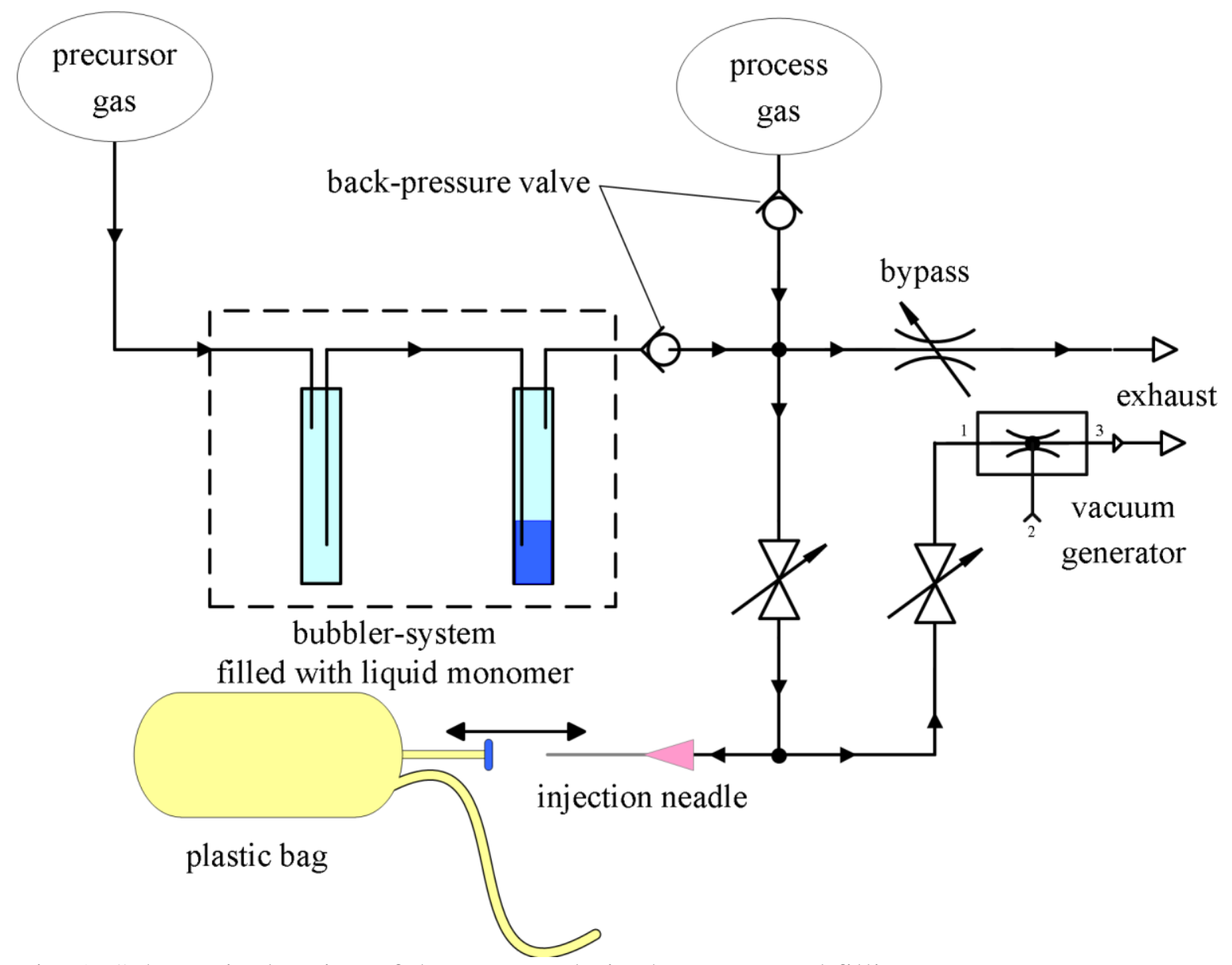

Fig. 1: Schematic drawing of the gas supply in the automated filling system. 


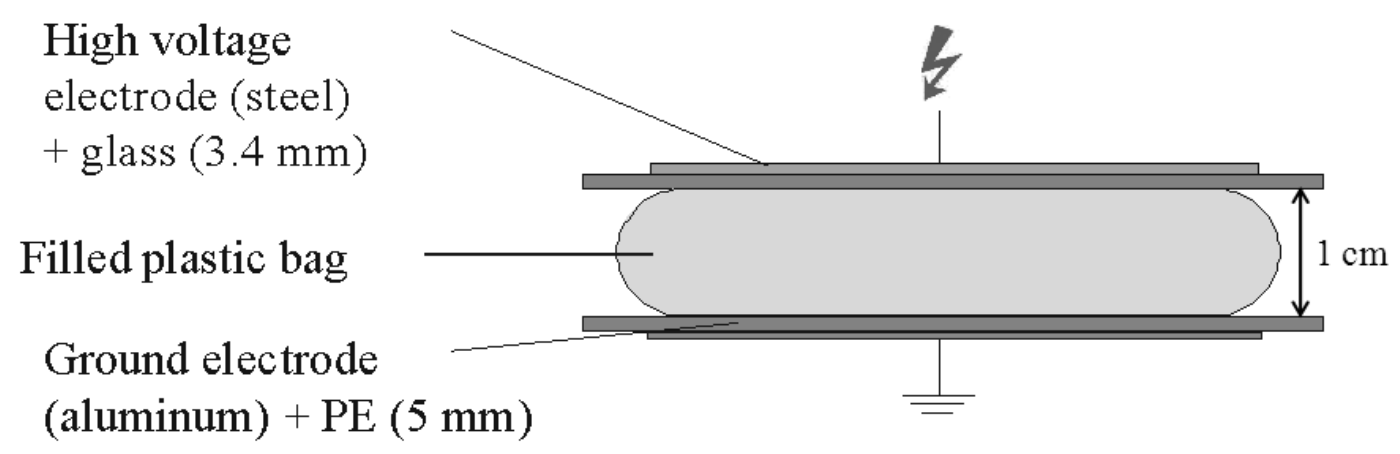

Fig. 2: Schematic illustration of the electrode arrangement used for plasma treatment 

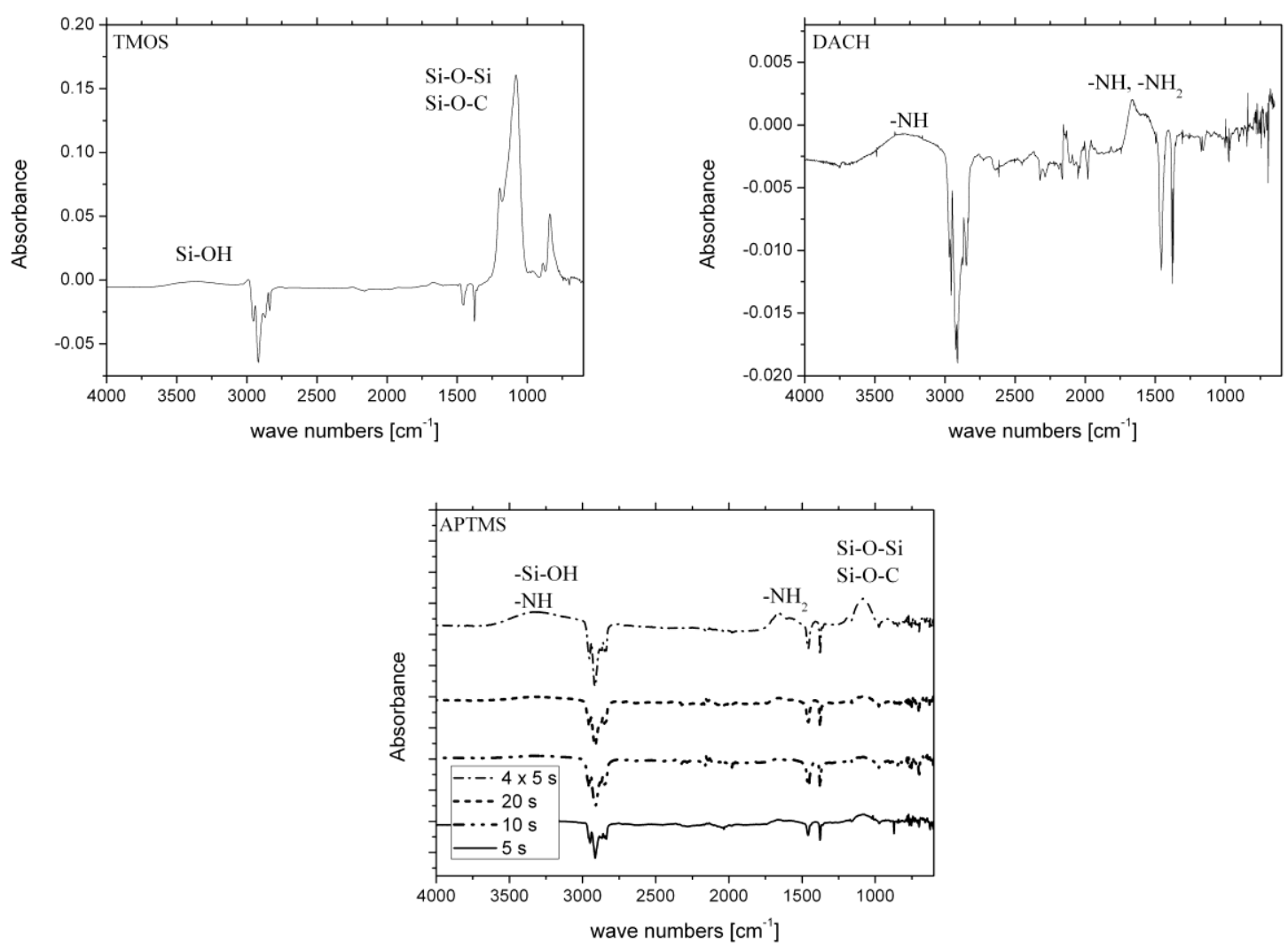

Fig. 3: FTIR-ATR difference spectra of plastic bag coated with tetramethoxysilane (top left), 1.2-diaminocyclohexane (top right) and 3-aminopropyl-trimethoxysilane (bottom). Substraterelated absorptions bands were eliminated by subtracting the FITR-spectrum of an untreated polymer bag from the spectrum obtained after the treatment. The negative absorption bands in the spectra arise due to the attenuation of the substrate absorption because of film formation. 


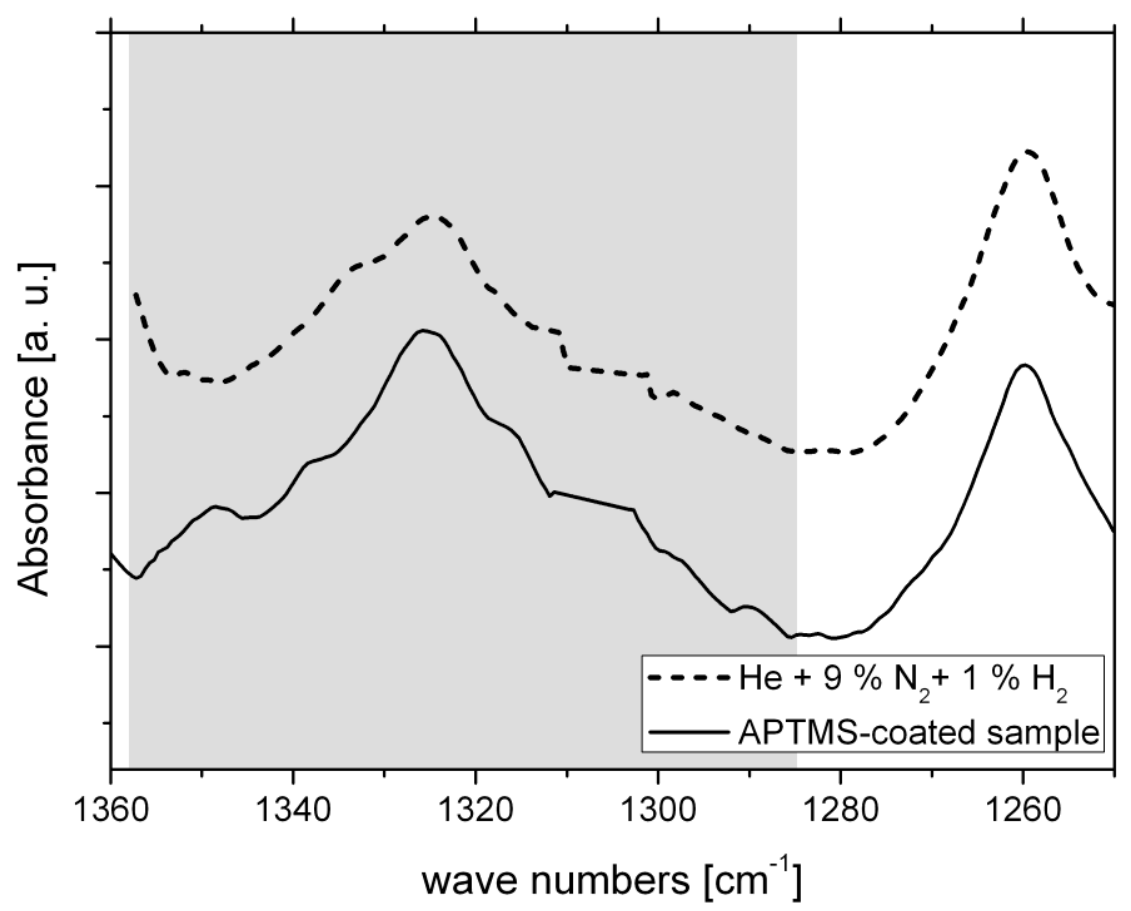

Fig. 4: FTIR-ATR different spectra of two modified samples after chemical derivatization with 4-trifluoromethyl-benzaldehyde (TFBA). The number densitiy of primary amino groups can be determined from the area of the extinction band of the $-\mathrm{CF}_{3}$ group introduced by the reaction of primary amino groups with TFBA. For more details see Ref [24]. The band at $1260 \mathrm{~cm}^{-1}$ is related to an absorption of polypropylene which could not be eliminated during subtraction because of small differences in the intensity of the spectra of the underivatized and the derivatized sample. 

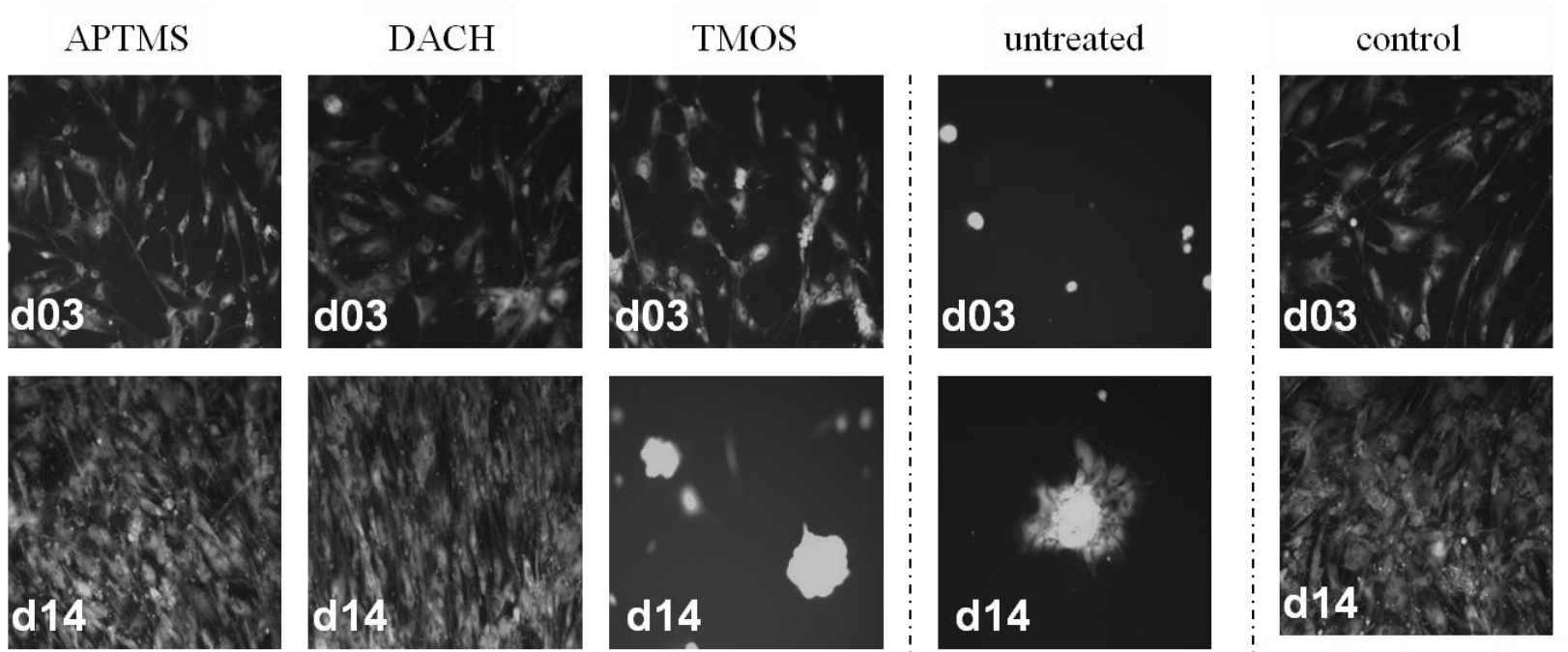

Fig. 5: Cell cultivation of adherent bone marrow mesenchymal stem cells on the modified plastic bags at day 3 of cultivation (above) and at day 14 of cultivation (below). As control serves a commercial availiable cell culture plate, magnification 10x. 
Tables:

Table 1: Process parameters for the plasma treatment of the closed bag systems.

\begin{tabular}{lcccc}
\hline $\begin{array}{l}\text { Gas mixture / film- forming } \\
\text { agent }\end{array}$ & $\begin{array}{l}\text { Total gas } \\
\text { flow L min } \\
\text { STP }\end{array}$ & $\begin{array}{l}\text { Precursor gas } \\
\text { flow L min } \\
\text { STP }\end{array}$ & P[W] & $\mathbf{U}_{\text {eff }}[\mathbf{k V}]$ \\
\hline $\mathrm{He}$ & 5 & 0 & 50 & \\
$\mathrm{He}+\mathrm{N}_{2}$ and $\mathrm{H}_{2}$ & 5 & $0.5^{*}$ & 100 & 16.5 \\
$\begin{array}{l}\mathrm{He}+3-\text {-Aminopropyl- } \\
\text { trimethoxysilane (APTMS) }\end{array}$ & 5 & 5 & 50 & 9.75 \\
$\begin{array}{l}\mathrm{He}+1.2-\text {-Diamino-cyclohexane } \\
\text { (DACH) }\end{array}$ & 5 & 5 & 50 & 9.75 \\
$\begin{array}{l}\text { He }+ \text { Tetramethoxysilane } \\
\text { (TMOS) }\end{array}$ & 5 & 2 & 50 & 9.75 \\
\hline
\end{tabular}

$* \mathrm{~N}_{2}$ with $10 \% \mathrm{H}_{2}$ 
Table 2: Gas mixture and film-forming agent and created surface functional groups.

\begin{tabular}{ll}
\hline $\begin{array}{l}\text { Gas mixture / film- forming } \\
\text { agent }\end{array}$ & Surface functional groups \\
\hline $\mathrm{He}$ & $\mathrm{O}-$ containing groups \\
$\mathrm{He}+\mathrm{N}_{2}+\mathrm{H}_{2}$ & $-\mathrm{NH}_{2},-\mathrm{NH}$ \\
$\mathrm{He}+\mathrm{APTMS}$ & $-\mathrm{NH}_{2}, \mathrm{Si}-\mathrm{OH}$ \\
$\mathrm{He}+\mathrm{DACH}$ & $-\mathrm{NH}_{2}$ \\
$\mathrm{He}+\mathrm{TMOS}$ & $\mathrm{Si}-\mathrm{OH}$ \\
\hline
\end{tabular}


Table 3: Surface tension components and total surface tensions $[\mathrm{mN} / \mathrm{m}]$ of the treated polymer depending on the gas mixture and the film-forming agent, resp., after $10 \mathrm{~s}$ of plasma treatment.

\begin{tabular}{lccccc}
\hline $\begin{array}{l}\text { Gas mixture / film- } \\
\text { forming agent }\end{array}$ & $\gamma_{\text {total }}[\mathbf{m N} / \mathbf{m}]$ & $\gamma_{\mathbf{L W}}$ & $\gamma_{\mathbf{A B}}$ & $\gamma^{+}$ & $\gamma^{-}$ \\
\hline $\mathrm{He}$ & 34.9 & 34.5 & 0.4 & 0.04 & 9.0 \\
$\mathrm{He}+9 \% \mathrm{~N}_{2}+1 \% \mathrm{H}_{2}$ & 36.1 & 33.0 & 3.1 & 0.3 & 8.6 \\
$\mathrm{He}+\mathrm{APTMS}$ & 37.7 & 34.1 & 3.6 & 0.3 & 9.5 \\
$\mathrm{He}+\mathrm{DACH}$ & 41.1 & 40.8 & 0.3 & 0.002 & 9.9 \\
$\mathrm{He}+\mathrm{TMOS}$ & 36.5 & 35.1 & 1.1 & 0.02 & 14.4 \\
Polypropylene untreated & 26.3 & 26.3 & 0 & 0 & 0 \\
\hline
\end{tabular}


Table 4: Element composition determined by XPS of helium-treated polymer samples.

\begin{tabular}{lrrr}
\hline Sample/Element & C [\%] & \multicolumn{1}{c}{ O [\%] } & $\mathbf{S i}^{*}[\%]$ \\
\hline He -5 s treated & 89.7 & 10.17 & 0.13 \\
untreated & 95.14 & 4.86 & 0 \\
\hline
\end{tabular}

* $\mathrm{Si}$ is attributed to silicon organic contaminations on the surface 
Table 5: Element composition determined by XPS of helium-treated polymer samples with admixtures of $\mathrm{N}_{2}$ and $\mathrm{H}_{2}$.

\begin{tabular}{lrrrr}
\hline Sample / Element & C [\%] & N [\%] & O [\%] & F [\%] \\
\hline $\mathrm{He}+9 \% \mathrm{~N}_{2}+1 \% \mathrm{H}_{2}$ & 89 & 1.62 & 9.38 & \\
derivatized samples & 85.68 & 2.17 & 11.56 & 0.58 \\
\hline
\end{tabular}

